\title{
SOLAR ACTIVITY AND EARTH SEISMICITY
}

\author{
V.L. Yanchukovsky \\ A.A. Trofimuk Institute of Oil and Gas Geology and Geophyscs SB RAS, \\ Novosibirsk, Russia,YanchukovskiyVL@ipgg.sbras.ru
}

\begin{abstract}
Using the results of continuous long-term observations over 50 years (including solar cycles 2024), we study the relationship between Earth's seismicity and solar activity. An increase in the number of strong earthquakes on the planet occurs during the decline phase of solar activity when charged particle fluxes from high-latitude coronal holes increase, as well as during solar minimum when the intensity of galactic cosmic rays reaches a maximum. The change in the number of strong earthquakes (with magnitude 6) is considered in terms of variations in the intensity of galactic cosmic rays, Forbush decreases, and ground level enhancements in solar cosmic rays (GLE events). The number of strong earthquakes is shown to increase after Forbush decreases with a time lag from $\sim 1$ to $\sim 6$ days depending on the amplitude of Forbush decrease, and after ground level enhancements in solar cosmic rays
\end{abstract}

(GLE events), the number of strong earthquakes increases by $\sim 8$ day. In the number of strong earthquakes, a six-month variation is observed, which seems to follow the six-month variation in cosmic rays with a delay of 1-2 months. It is surmised that the relationship between solar activity and Earth's seismicity seems to be mediated through the modulation of galactic cosmic rays and atmospheric processes that provoke the occurrence of earthquakes in regions where the situation has already been prepared by tectonic activity.

Keywords: solar activity, cosmic rays, atmosphere, seismicity.

\section{INTRODUCTION}

The presence of a link between Earth's seismicity and 11-year cycle of solar activity (SA) was indicated by Pierre Bernard as far back as 1938 [Russo, 1966]. Unfortunately, due to lack of long series of instrumental seismic observations, the relationship between the time of occurrence of earthquakes and solar processes was not explored. The results of research into processes occurring on the Sun and in the interplanetary medium, the massive amount of instrumental seismic observations, the use of an energy classification of earthquakes provided a more detailed study of the relationship between Earth's seismicity and solar activity [Sytinsky, 1989]. The analysis of instrumental seismic observations for 1909-1926 and 1962-1977 has shown an increase in Earth's seismicity near the maximum and minimum of the 11-year solar cycle. As a solar activity index Wolf numbers $(W)$ were utilized, and hence solar wind parameters and the interplanetary magnetic field (IMF) strength and direction were left out of account. Moreover, it also happens that there are no sunspots at all (for example, late 2008 - early 2009), but this does not imply zero solar activity.

\section{DATA}

Variations in solar activity (Wolf numbers) [http://www.wdcb.ru/stp/solar/sunspots.ru.html; http://www.meteo-dv.ru/geospace/AverageMonthW; http://sidc.oma.be] and cosmic ray (CR) intensity, as derived from data obtained at the mid-latitude station Novosibirsk [http://cosm-rays.ipgg.sbras.ru] over a long observation period (more than half a century), are depicted in Figure 1. Until 1969, we used data from a cubic-geometry neutron monitor with neutron counters
SNM-8 [Yanchukovsky et al., 1971]. The data is normalized to data from the neutron monitor NM-64 (with neutron counters SNM-15) [Hatton, Carmichael, 1964], which started continuous recording in 1969.

The correlation coefficient of annual values of the count rate of the neutron monitor and Wolf numbers over the period is -0.87 . This indicates sufficient data consistency. The CR flux is a more objective characteristic of solar activity, albeit indirect. Cosmic rays as a flux of charged particles (mostly protons) are affected by solar wind and IMF. This explains the almost instantaneous response of CR to variations in IMF and solar wind parameters, caused, for example, by explosions on the Sun. So, information about processes on the Sun and in the interplanetary medium is passed on through modulation of background cosmic rays. In this regard, it is interesting to examine temporal regularities of global seismicity and CR intensity variations, using continuous high-precision observations over a long period (from solar cycle 20 to solar cycle 24).

Study of Earth's total seismicity usually relies on the energy characteristic of earthquakes - magnitude $(M)$ [Gutenberg, Richter, 1954]. The spectrum of earthquakes in magnitudes $N=f(M)$ is steeply-falling. The energy of earthquakes is related to magnitude by the empirical relation $\lg E=11.8+1.5 \mathrm{M}$, therefore the total energy of earthquakes $\Sigma E$ is determined by the energy of strong earthquakes. Contribution of weak earthquakes $(M \leq 6)$ in $\Sigma E$ is a fraction of one percent [Sytinsky, 1989], therefore an increase in statistics (number $N$ ) at the cost of weak earthquakes leads to gross errors [Sytinsky, 1989]. Accordingly, when considering time characteristics of global seismicity, we use information about strong earthquakes $(M \geq 6)$. Along with data from the global network of CR stations 


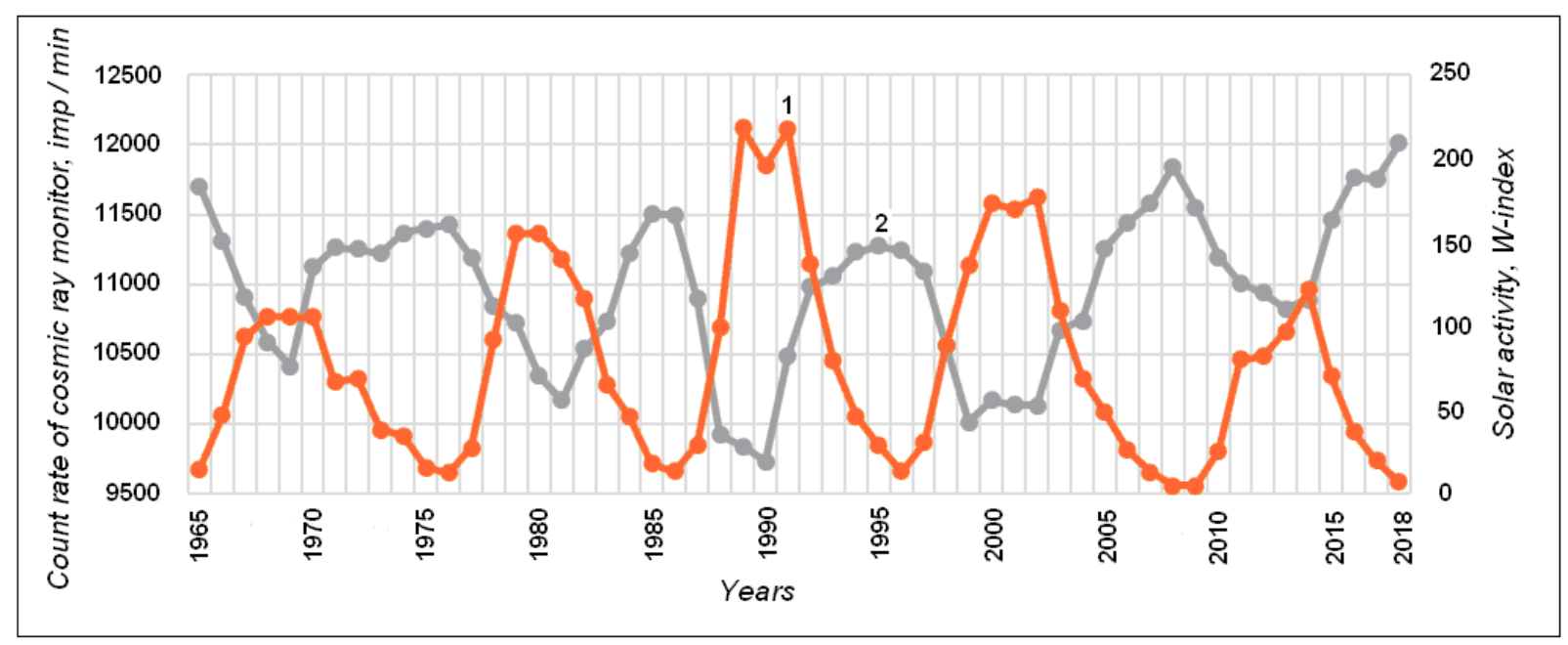

Figure 1. Annual average values of Wolff numbers (curve 1) and count rate of the neutron monitor 24NM-64 at the CR station Novosibirsk (curve 2)

[http://www.nmdb.eu], we have utilized results of CR continuous observations (from 1970) obtained at the station Novosibirsk with a neutron monitor 24NM-64 (with an effective area of $24 \mathrm{~m}^{2}$ ) [Yanchukovsky 2010; http://193.232.24.200/nvbk/ main.htm] and results of statistical processing of earthquake data [https://earthquake.usgs.gov/earthquakes] for 1970 2019. Statistics on strong earthquakes for the same period is presented in Table 1 . The total number of severe earthquakes over the said period is 4306 .

Table 1

Monthly number of strong earthquakes over the period $1970-2019$

\begin{tabular}{|c|c|c|c|c|c|c|c|c|c|c|c|c|c|}
\hline Y M & 1 & 2 & 3 & 4 & 5 & 6 & 7 & 8 & 9 & 10 & 11 & 12 & $\begin{array}{c}\text { In } \\
\text { total }\end{array}$ \\
\hline 1970 & 8 & 4 & 6 & 9 & 5 & 10 & 7 & 8 & 7 & 6 & 4 & 8 & 82 \\
\hline 1971 & 4 & 6 & 4 & 4 & 7 & 4 & 16 & 9 & 9 & 9 & 3 & 5 & 81 \\
\hline 1972 & 12 & 3 & 7 & 10 & 7 & 3 & 2 & 6 & 9 & 5 & 4 & 5 & 73 \\
\hline 1973 & 2 & 4 & 3 & 6 & 0 & 5 & 5 & 4 & 4 & 6 & 2 & 6 & 47 \\
\hline 1974 & 4 & 2 & 3 & 0 & 4 & 2 & 5 & 4 & 3 & 7 & 3 & 3 & 41 \\
\hline 1975 & 3 & 4 & 5 & 4 & 3 & 2 & 7 & 3 & 3 & 13 & 2 & 3 & 53 \\
\hline 1976 & 6 & 1 & 3 & 3 & 9 & 6 & 7 & 7 & 1 & 2 & 9 & 2 & 56 \\
\hline 1977 & 4 & 2 & 4 & 5 & 0 & 1 & 3 & 5 & 4 & 4 & 4 & 3 & 39 \\
\hline 1978 & 3 & 3 & 11 & 2 & 4 & 6 & 2 & 3 & 2 & 0 & 4 & 5 & 45 \\
\hline 1979 & 4 & 4 & 1 & 3 & 2 & 2 & 2 & 4 & 2 & 7 & 6 & 3 & 40 \\
\hline 1980 & 1 & 5 & 5 & 1 & 1 & 4 & 9 & 3 & 1 & 8 & 9 & 3 & 43 \\
\hline 1981 & 7 & 3 & 2 & 2 & 3 & 2 & 4 & 0 & 4 & 4 & 5 & 6 & 41 \\
\hline 1982 & 7 & 2 & 3 & 1 & 4 & 6 & 4 & 5 & 6 & 0 & 4 & 8 & 50 \\
\hline 1983 & 9 & 5 & 7 & 8 & 5 & 7 & 6 & 5 & 5 & 14 & 6 & 10 & 87 \\
\hline 1984 & 5 & 4 & 5 & 7 & 6 & 4 & 4 & 5 & 5 & 7 & 11 & 5 & 68 \\
\hline 1985 & 3 & 1 & 17 & 7 & 8 & 7 & 8 & 7 & 8 & 8 & 6 & 9 & 89 \\
\hline 1986 & 2 & 1 & 6 & 5 & 11 & 9 & 6 & 9 & 5 & 9 & 3 & 6 & 72 \\
\hline 1987 & 9 & 9 & 8 & 8 & 8 & 8 & 5 & 3 & 9 & 11 & 7 & 4 & 88 \\
\hline 1988 & 5 & 10 & 4 & 5 & 4 & 5 & 10 & 7 & 1 & 3 & 9 & 3 & 67 \\
\hline 1989 & 4 & 6 & 1 & 7 & 8 & 3 & 4 & 8 & 5 & 6 & 3 & 7 & 62 \\
\hline 1990 & 2 & 6 & 9 & 11 & 14 & 8 & 8 & 6 & 6 & 4 & 5 & 6 & 85 \\
\hline 1991 & 7 & 4 & 4 & 8 & 8 & 8 & 5 & 4 & 4 & 6 & 7 & 14 & 80 \\
\hline 1992 & 1 & 4 & 8 & 6 & 10 & 5 & 6 & 12 & 7 & 12 & 6 & 5 & 82 \\
\hline 1993 & 6 & 2 & 9 & 7 & 9 & 8 & 4 & 10 & 12 & 7 & 2 & 5 & 82 \\
\hline 1994 & 5 & 9 & 5 & 6 & 6 & 8 & 7 & 4 & 4 & 11 & 4 & 7 & 76 \\
\hline
\end{tabular}

\begin{tabular}{|l|l|l|l|l|l|l|l|l|l|l|l|l|l|}
\hline 1995 & 8 & 8 & 2 & 11 & 15 & 5 & 6 & 13 & 3 & 12 & 8 & 11 & 103 \\
\hline
\end{tabular} \begin{tabular}{|l|l|l|l|l|l|l|l|l|l|l|l|l|l|}
\hline 1996 & 3 & 13 & 8 & 3 & 2 & 12 & 6 & 4 & 7 & 8 & 6 & 5 & 77 \\
\hline
\end{tabular} \begin{tabular}{|l|l|l|l|l|l|l|l|l|l|l|l|l|l|}
\hline 1997 & 3 & 3 & 4 & 5 & 10 & 4 & 4 & 6 & 3 & 7 & 6 & 6 & 61 \\
\hline
\end{tabular} \begin{tabular}{|c|c|c|c|c|c|c|c|c|c|c|c|c|c|}
\hline 1998 & 11 & 5 & 5 & 4 & 8 & 5 & 6 & 6 & 5 & 2 & 6 & 2 & 65 \\
\hline
\end{tabular} \begin{tabular}{|l|l|l|l|l|l|l|l|l|l|l|l|l|l|}
\hline 1999 & 5 & 3 & 5 & 6 & 4 & 4 & 4 & 8 & 10 & 4 & 10 & 12 & 75 \\
\hline
\end{tabular} \begin{tabular}{|l|l|l|l|l|l|l|l|l|l|l|l|l|l|}
\hline 2000 & 6 & 3 & 6 & 2 & 6 & 15 & 6 & 10 & 4 & 7 & 13 & 7 & 85 \\
\hline
\end{tabular} \begin{tabular}{|l|l|l|l|l|l|l|l|l|l|l|l|l|l|}
2001 & 13 & 9 & 3 & 5 & 8 & 6 & 8 & 6 & 5 & 7 & 5 & 7 & 82 \\
\hline
\end{tabular} \begin{tabular}{|l|l|l|l|l|l|l|l|l|l|l|l|l|l|}
2002 & 8 & 4 & 8 & 5 & 2 & 12 & 1 & 6 & 9 & 9 & 11 & 4 & 79 \\
\hline
\end{tabular} \begin{tabular}{|c|c|c|c|c|c|c|c|c|c|c|c|c|c|}
\hline 2003 & 7 & 8 & 7 & 7 & 13 & 8 & 7 & 4 & 11 & 7 & 7 & 12 & 98 \\
\hline
\end{tabular} \begin{tabular}{|l|l|l|l|l|l|l|l|l|l|l|l|l|l|}
\hline 2004 & 5 & 8 & 2 & 5 & 6 & 8 & 8 & 2 & 11 & 9 & 16 & 8 & 88 \\
\hline
\end{tabular} \begin{tabular}{|l|l|l|l|l|l|l|l|l|l|l|l|l|l|}
\hline 2005 & 11 & 15 & 9 & 11 & 10 & 9 & 6 & 2 & 8 & 8 & 6 & 8 & 105 \\
\hline
\end{tabular} \begin{tabular}{|l|l|l|l|l|l|l|l|l|l|l|l|l|l|}
\hline 2006 & 6 & 5 & 2 & 8 & 9 & 6 & 7 & 8 & 9 & 12 & 8 & 8 & 88 \\
\hline
\end{tabular} \begin{tabular}{|l|l|l|l|l|l|l|l|l|l|l|l|l|l|}
\hline 2007 & 8 & 6 & 8 & 12 & 4 & 7 & 9 & 14 & 21 & 9 & 13 & 7 & 118 \\
\hline
\end{tabular} \begin{tabular}{|l|l|l|l|l|l|l|l|l|l|l|l|l|l|}
\hline 2008 & 7 & 19 & 7 & 19 & 12 & 7 & 9 & 9 & 6 & 10 & 10 & 11 & 126 \\
\hline
\end{tabular} \begin{tabular}{|l|l|l|l|l|l|l|l|l|l|l|l|l|l|}
\hline 2009 & 11 & 3 & 9 & 13 & 10 & 7 & 7 & 13 & 11 & 18 & 7 & 7 & 117 \\
\hline
\end{tabular} \begin{tabular}{|l|l|l|l|l|l|l|l|l|l|l|l|l|l|}
\hline 2010 & 14 & 16 & 20 & 22 & 19 & 13 & 18 & 13 & 11 & 8 & 6 & 11 & 171 \\
\hline
\end{tabular} \begin{tabular}{|l|l|l|l|l|l|l|l|l|l|l|l|l|l|}
\hline 2011 & 9 & 13 & 35 & 13 & 6 & 11 & 13 & 13 & 19 & 11 & 11 & 6 & 160 \\
\hline
\end{tabular} \begin{tabular}{|l|l|l|l|l|l|l|l|l|l|l|l|l|l|}
\hline 2012 & 15 & 11 & 11 & 12 & 12 & 12 & 8 & 14 & 8 & 14 & 8 & 6 & 131 \\
\hline
\end{tabular} \begin{tabular}{|l|l|l|l|l|l|l|l|l|l|l|l|l|l|}
\hline 2013 & 4 & 17 & 6 & 15 & 15 & 7 & 10 & 11 & 9 & 13 & 9 & 4 & 120 \\
\hline
\end{tabular} \begin{tabular}{|l|l|l|l|l|l|l|l|l|l|l|l|l|l|}
\hline 2014 & 7 & 6 & 19 & 18 & 20 & 14 & 10 & 12 & 3 & 6 & 13 & 8 & 136 \\
\hline
\end{tabular} \begin{tabular}{|l|l|l|l|l|l|l|l|l|l|l|l|l|l|}
\hline 2015 & 8 & 8 & 6 & 11 & 20 & 7 & 13 & 4 & 18 & 6 & 17 & 10 & 128 \\
\hline
\end{tabular} \begin{tabular}{|l|l|l|l|l|l|l|l|l|l|l|l|l|l|}
\hline 2016 & 13 & 10 & 6 & 12 & 6 & 9 & 7 & 11 & 15 & 9 & 14 & 20 & 132 \\
\hline
\end{tabular}

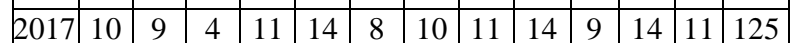
\begin{tabular}{|l|l|l|l|l|l|l|l|l|l|l|l|l|l|}
\hline 2018 & 10 & 8 & 6 & 2 & 4 & 2 & 4 & 21 & 12 & 14 & 10 & 13 & 106 \\
\hline
\end{tabular} \begin{tabular}{|l|l|l|l|l|l|l|l|l|l|l|l|l|l|}
\hline 2019 & 7 & 4 & 7 & 11 & 9 & 15 & 9 & 7 & 9 & 6 & 13 & 5 & 102 \\
\hline
\end{tabular}

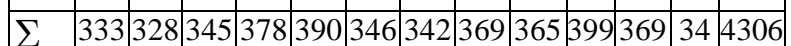
9

\section{DISTRIBUTION OF THE NUMBER OF EARTHQUAKES AND COSMIC RAY INTENSITY OVER A LONG PERIOD}

The relationship between the total annual energy of earthquakes and the CR intensity (from data acquired with the high-latitude neutron monitor Apatity) has been considered before [Sobolev et al., 1998] for the period from 1975 to 1987 , i.e. only for one solar cycle (21). The correlation coefficient in the period of interest is 0.82 , but a question arises as to whether such a suffi- 
ciently close relationship is observed in a larger time interval, for example, for several solar cycles.

Figure 2, $a$ shows CR intensity variations, presented as a count rate of the neutron monitor, and the number of earthquakes per year with $M \geq 6$ over a long observation period. When comparing the number of strong earthquakes per year $N(t)$ and CR intensity $I(t)$ for nearly five SA cycles, it is difficult to conclude about very high regularity of the relationship between SA and global seismicity, as is done in [Sytinsky, 1989] by the example of only two solar cycles (15 and 20) and in [Sobolev et al., 1998] by the example of one solar cycle (21). In the temporal distribution of the number of strong earthquakes $N(t)$ with $M \geq 6$ in the period of interest there is a significant linear trend $N(t)=a+b t(a=40.905 ; b=1.575)$, shown in Figure 2 , $a$ (orange line). We singly smoothed raw data (Figure 2, a), using a moving average with a step equal to 3 , and took the linear trend into account. The results are presented in Figure 2, $b$.

Continuous series of data for the last five SA cycles and the epoch overlay method were used to obtain distributions of Wolf numbers $W, \mathrm{CR}$ intensity, and the number of strong earthquakes in terms of the SA phase. The CR intensity is represented as the count rate of the neutron monitor of the station Novosibirsk. As a reference year, the year with a maximum Wolf number is taken. The resulting distributions are shown in Figure 3.

There is a positive correlation between a change in the number of strong earthquakes and the CR intensity, with the greatest changes in the number of earthquakes occurring during periods when the rate of CR intensity variation in the SA cycle is maximum. The number of strong earthquakes increases during the decline phase of solar activity, when charged particle fluxes from highlatitude coronal holes enhance, and also during the SA minimum, when the $\mathrm{CR}$ intensity is maximum.

\section{DISTRIBUTION OF THE NUMBER OF STRONG EARTHQUAKES DURING SPORADIC COSMIC RAY INTENSITY VARIATIONS}

In the first place among sporadic SR intensity variations are Forbush effects (Forbush decreases, FD), which are usually caused by powerful solar flares. A Forbush decrease is a sharp, for several hours, decrease in the CR intensity, followed by its slower (sometimes for 15 days) recovery. For the period from 1968 to 2018, 185 FD have been examined, 90 of the events with an amplitude from 2.5 to $4 \%$; 65 , with an amplitude from 5 to $7 \%$; and 30, with an amplitude of at least $8 \%$. The number of FD drops with increasing amplitude of the effect. Also small is statistics of strong earthquakes.

The relationship of strong earthquakes $(M \geq 6)$ with FD was examined using the epoch overlay method. As a reference day, the day of the beginning of FD (FD front) is taken. The results are presented in Figure 4.

Distribution of the number $N$ of strong earthquakes $(M \geq 6$ ) with respect to the FD front (Figure 4) is shown for different amplitudes of CR intensity decreases. A slight increase in $N$ during FD with an amplitude of $\geq 8$ $\%$ occurs one day after the beginning of the CR intensity decrease; for FD by 5-7\%, on the first and fourth day; and for FD by $2.5-4 \%$, on the first and sixth day. Therefore, in the distribution of the number of strong earthquakes, illustrated in Figure 5, for all 185 events considered there are three maxima, the highest occurring on the sixth day.

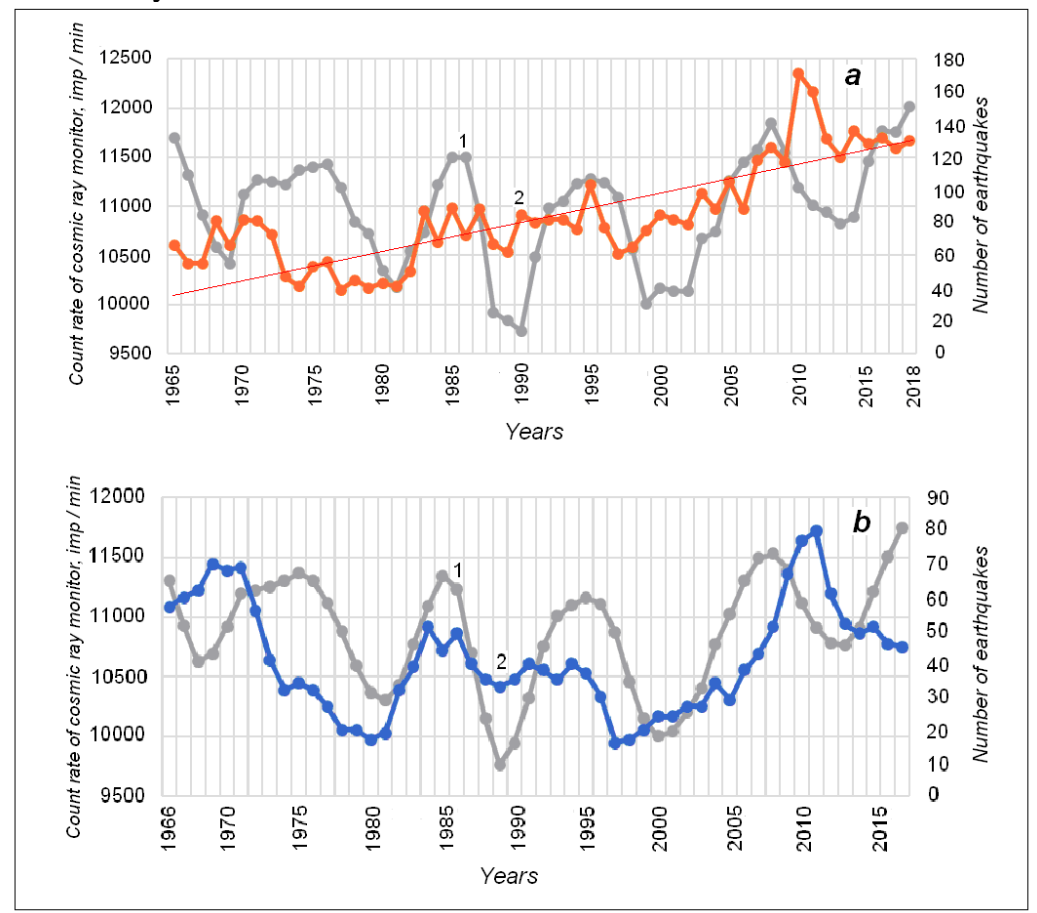

Figure 2. Eleven-year CR variations (curve 1) and variations in the number of strong earthquakes (curve 2): $a$ - raw data; $b$ - smoothed data with linear trends taken into account 


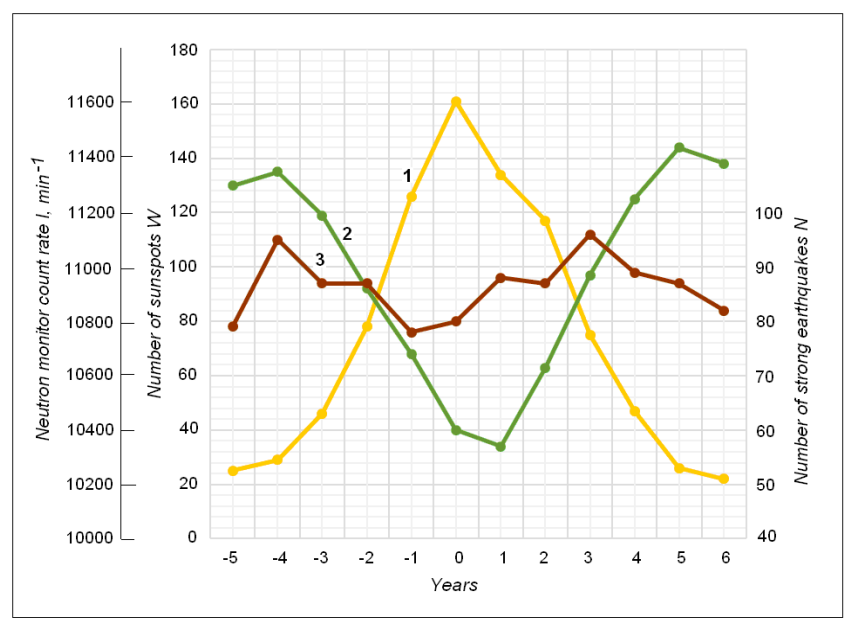

Figure 3. Distribution of Wolff numbers (curve 1), count rate of a neutron monitor (curve 2), and the number of strong earthquakes (curve 3) in a solar cycle

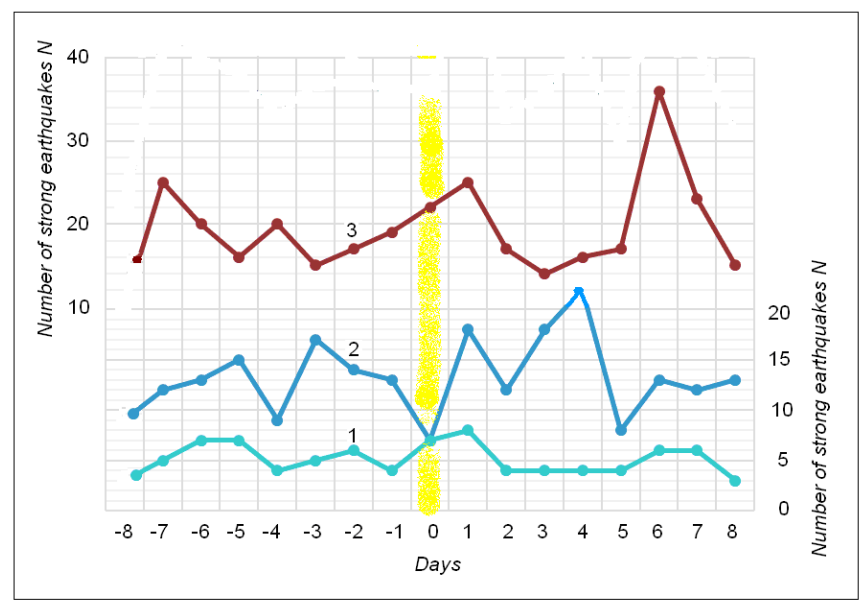

Figure 4. Distribution of the number of strong earthquakes with respect to the front of Forbush decreases with amplitudes of $\geq 8 \%$ (curve 1, right scale), 5-7\% (curve 2, right scale), $2.5-4 \%$ (curve 3, left scale)

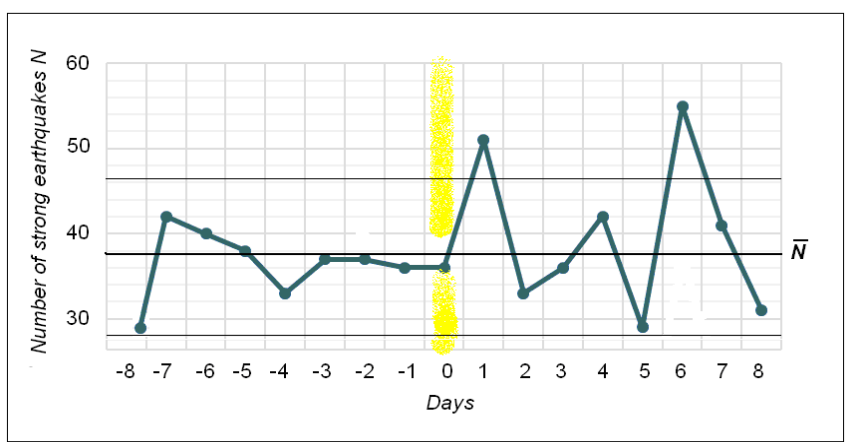

Figure 5. Distribution of the number $N$ of strong earthquakes with respect to the FD front for 185 FD over the period from 1968 to 2018. Thin lines are confidence limits $\bar{N} \pm 3 \sigma$

Sporadic CR intensity variations also include solar CR flares caused by solar proton events (SPE), recorded on Earth as so-called ground level enhancements (GLE) of the solar CR intensity. The CR variations observed during GLE with neutron monitors may sometimes exceed the 11-year variation and the largest CR Forbush decreases by more than an order of magnitude. GLE of the solar CR intensity are fairly rare events - less than $5 \%$ of all solar proton events. On the average, one GLE event occurs per year. The last GLE was recorded on
December 13, 2006. In total, 18 events have been recorded with the neutron monitor 24NM-64 at the midlatitude CR station Novosibirsk over 50 years, which then have been used to study the relationship between GLE and strong earthquakes. Distribution of the number of strong earthquakes with respect to the date of GLE, obtained by the epoch overlay method, is shown in Figure 6. As a reference day, the day when a CR flare occurred is taken. The maximum number of strong earthquakes is observed on the eighth day after the CR flare. 


\section{COSMIC RAY VARIATIONS DURING STRONG EARTHQUAKES}

Let us consider $\mathrm{CR}$ variations with respect to the date of the beginning of the severest earthquakes $(M \geq 7)$ for the period of interest [https://earthquake.usgs. gov/earthquakes/browse/significant.php; http://www. russtat.ru/index.php?vid=1\&year=2001\&id=49 \& page=2]. Information about these earthquakes is given in Table 2 . The result received by the epoch overlay method is shown in Figure 7. As a reference day the day of the beginning of an earthquake is taken.

In the period from 18 to 4 days prior to the beginning of an earthquake there are CR intensity variations with an amplitude of $\sim 1.5 \%$ (Figure 7). The CR intensity variation in this period appears as a strong (long) bipolar pulse with a high positive amplitude.

\section{SEMIANNUAL VARIATION IN THE COSMIC RAY INTENSITY AND SEASONAL DISTRIBUTION OF THE NUMBER OF STRONG EARTHQUAKES}

The extra-atmospheric nature of seasonal CR intensity variations with peaks during equinoxes was first mentioned in [Dorman et al., 1967]. Results of subsequent theoretical and experimental studies of the nature of annual and semiannual CR intensity variations are reported in [Krymsky et al., 1981, 2007, 2009, 2012; Belov et al., 2015], etc. The following facts have been found. The semiannual and annual CR intensity varia- tions are caused, on the one hand, by the presence of the heliolatitude gradient of the CR density, which is due to the north-south asymmetry in the low-latitude heliosphere; and, on the other hand, by the position and opening of the IMF neutral layer, as well as by the asymmetry in activity of solar hemispheres [Krymsky et al., 2007, 2009, 2012; Belov et al., 2015].

The seasonal CR flux distribution in the atmosphere has been assessed using neutron monitor data. Monthly averages of the count rate of neutron monitors of the global network for 1970-2019, corrected for meteorological effects, were used [http://www.nmdb.eu]. A seasonal CR intensity variation at CR stations of the Northern $(a)$ and Southern $(b)$ hemispheres is shown in Figure 8. Coordinates of the CR stations, altitude, neutron monitor type, as well as references to websites of the stations are given in Table 3.

When determining the monthly averages, all data was consumed regardless of the solar cycle phase, including periods of strong FD and CR flares. It is easy to observe that the results received from data acquired at CR stations of the Northern Hemisphere are more consistent (Figure 8,a). This is accounted for the higher quality of the data: they are continuous, amassed with instruments of the same type, from a large effective area, which provides high statistical accuracy of recording. Among CR stations in the Southern Hemisphere, only the station Tsumeb has a device that is on a level with devices of $\mathrm{CR}$ stations in the Northern Hemisphere.

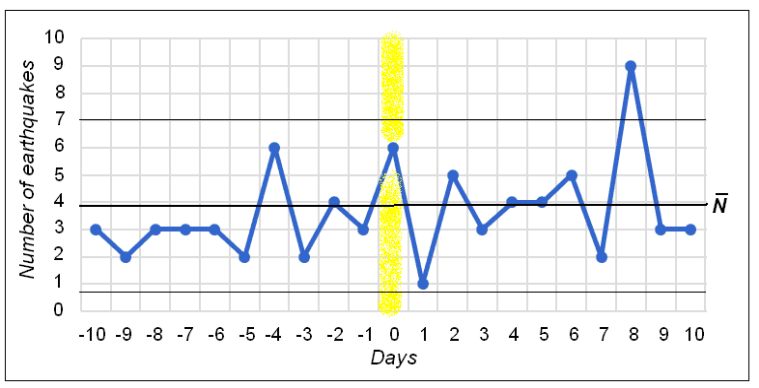

Figure 6. Distribution of the number of strong earthquakes relative to the date of GLE. Thin lines are confidence limits

Table 2

The strongest earthquakes over the past 50 years

\begin{tabular}{|c|l|l|c|}
\hline No. & \multicolumn{1}{|c|}{ Earthquake date } & \multicolumn{1}{|c|}{ Event location } & \multicolumn{1}{|c|}{$\begin{array}{c}\text { Magnitude } \\
\text { on the Richter scale }\end{array}$} \\
\hline 1 & 1966, April 26 & USSR, Uzbekistan, Tashkent & 5.2 \\
\hline 2 & 1970, May 31 & Peru & 7.9 \\
\hline 3 & 1971, September 6 & USSR, Sakhalin Island, Moneron & 7.3 \\
\hline 4 & 1972, February 4 & Guatemala, Honduras & 7.5 \\
\hline 5 & 1976, February 4 & Guatemala & 7.5 \\
\hline 6 & 1976, April 8 & USSR, Uzbekistan, Gazly & 7.0 \\
\hline 7 & 1976, July 28 & China, Tanshan & 7.4 \\
\hline 8 & 1977, March 4 & Romania, Bucharest & 7.5 \\
\hline 9 & 1978, September 16 & Iran, Thebes & 7.4 \\
\hline 10 & 1980, October 10 & Algeria, Al Asnam & 7.3 \\
\hline 11 & $\begin{array}{l}1985, \text { September 18 and } \\
19\end{array}$ & Mexico, Mexico City & 8.0 \\
\hline
\end{tabular}




\begin{tabular}{|l|l|l|c|}
\hline 12 & 1988, December 7 & Armenia, Spitak & 6.8 \\
\hline 13 & 1990, June 21 & Iran, the Caspian Sea area & 7.4 \\
\hline 14 & 1993, September 30 & India, Maharashtra & 7 \\
\hline 15 & 1995, May 27 & Russia, Sakhalin Island, Neftegorsk & 7.1 \\
\hline 16 & 1998, May 30 & Afghanistan & 6.6 \\
\hline 17 & 1999, August 17 & Turkey & 7.6 \\
\hline 18 & 1999, September 21 & Taiwan & 6.4 \\
\hline 19 & 2000, June 17 & Iceland & 6.5 \\
\hline 20 & 2000, August 5 & Russia, Sakhalin Island & 6.8 \\
\hline 21 & 2000, December 6 & Caspian region, Turkmenistan & 7.0 \\
\hline 22 & 2001, January 26 & India, Gujarat & 7.7 \\
\hline 23 & 2002, March 3 & Northern Afghanistan & 7.4 \\
\hline 24 & 2002, March 25 & Afghanistan & 7 \\
\hline 25 & 2003, December 26 & Southeast Iran & 6.6 \\
\hline 26 & 2004, December 26 & Indian Ocean, to the north of the Indonesian & 9.1 \\
\hline 27 & 2005, January 12 & island of Sumatra & 6.8 \\
\hline 28 & 2005, October 8 & Haiti & 7.6 \\
\hline 29 & 2008, May 12 & Pakistan & 7.9 \\
\hline 30 & 2010, January 12 & China, Sichuan Province & 7.0 \\
\hline 31 & 2010, February 27 & Chile & 8.8 \\
\hline 32 & 2011, March 11 & Japan, Honshu & 9.1 \\
\hline 33 & 2015, April 25 and 26 & Nepal & 7.8 \\
\hline
\end{tabular}

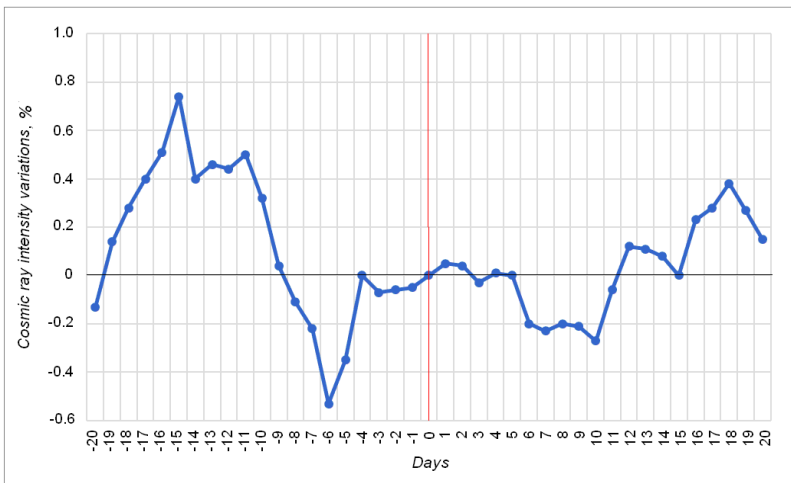

Figure 7. CR intensity distribution with respect to the beginning of an earthquake

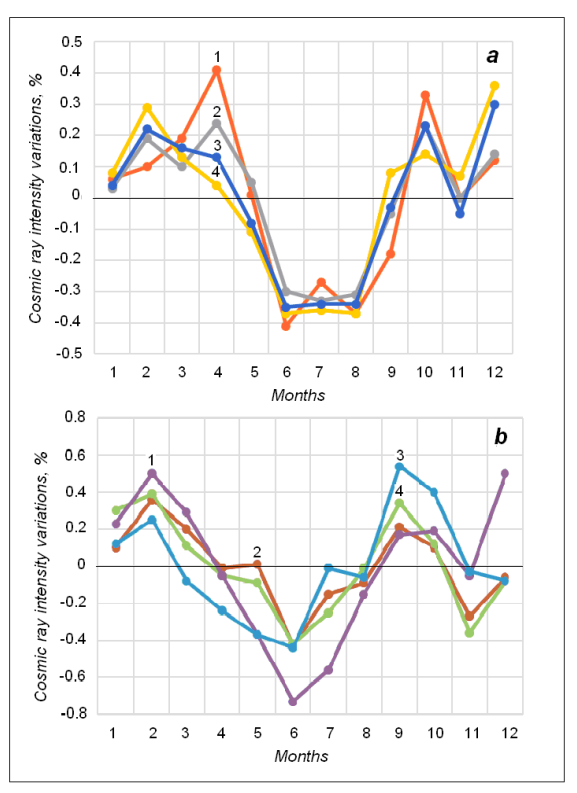

Figure 8. Seasonal CR intensity variation derived from neutron monitor data: $a-$ in the Northern Hemisphere $(1-$ Novosibirsk; 2 - Irkutsk; 3 - Ouly; 4 - Moscow); $b$ - in the Southern Hemisphere $(1$ - Hermanus; 2 - Potchefstroom; 3 Sanae; 4 - Tsumeb) 
CR stations of the World network

\begin{tabular}{|l|l|l|l|l|}
\hline $\begin{array}{l}\text { World network } \\
\text { cosmic ray station }\end{array}$ & Coordinates & Altitude & $\begin{array}{c}\text { Type } \\
\text { Instrument }\end{array}$ & \multicolumn{1}{c|}{ Link } \\
\hline $\begin{array}{l}\text { Novosibirsk, } \\
\text { Russia }\end{array}$ & $\begin{array}{l}54.48^{\circ} \mathrm{N} \\
83.0^{\circ} \mathrm{E}\end{array}$ & $163 \mathrm{~m}$ & $24-\mathrm{NM}-64$ & http://193.232.24.200/nvbk/main.htm \\
\hline $\begin{array}{l}\text { Irkutsk, } \\
\text { Russia }\end{array}$ & $\begin{array}{l}52.28^{\circ} \mathrm{N} \\
104.02^{\circ} \mathrm{E}\end{array}$ & $475 \mathrm{~m}$ & $18-\mathrm{NM}-64$ & http://cgm.iszf.irk.ru \\
\hline $\begin{array}{l}\text { Oulu, } \\
\text { Finland }\end{array}$ & $\begin{array}{l}67.05^{\circ} \mathrm{N}, \\
25.47^{\circ} \mathrm{E}\end{array}$ & $15 \mathrm{~m}$ & $18-\mathrm{NM}-64$ & http://cosmicrays.oulu.fi \\
\hline $\begin{array}{l}\text { Moscow, } \\
\text { Russia }\end{array}$ & $\begin{array}{l}55.47^{\circ} \mathrm{N} \\
37.32^{\circ} \mathrm{E}\end{array}$ & $200 \mathrm{~m}$ & $24-\mathrm{NM}-64$ & http://cr0.izmiran.ru/mosc \\
\hline $\begin{array}{l}\text { Hermanus, } \\
\text { South Africa }\end{array}$ & $\begin{array}{l}34.43^{\circ} \mathrm{S} \\
19.23^{\circ} \mathrm{E}\end{array}$ & $26 \mathrm{~m}$ & $12-\mathrm{NM}-64$ & $\begin{array}{l}\text { http://www.puk.ac.za/fakulteite/natuur/n } \\
\text { m_data/data/nmd_e.html }\end{array}$ \\
\hline $\begin{array}{l}\text { Potchefstroom, } \\
\text { South Africa }\end{array}$ & $\begin{array}{l}26.68^{\circ} \mathrm{S}, \\
27.09^{\circ} \mathrm{E}\end{array}$ & $1351 \mathrm{~m}$ & IGY NM & $\begin{array}{l}\text { http://www.puk.ac.za/fakulteite/natuur/n } \\
\text { m_data/data/nmd_e.html }\end{array}$ \\
\hline $\begin{array}{l}\text { Sanae, } \\
\text { Antarctica }\end{array}$ & $\begin{array}{l}71.66^{\circ} \mathrm{S}, \\
02.85^{\circ} \mathrm{W}\end{array}$ & $856 \mathrm{~m}$ & 3-NM-64 & $\begin{array}{l}\text { http://www.puk.ac.za/fakulteite/natuur/n } \\
\text { m_data/data/nmd_e.html }\end{array}$ \\
\hline $\begin{array}{l}\text { Tsumeb, } \\
\text { Namibia }\end{array}$ & $19.20^{\circ} \mathrm{S}$, & $1240 \mathrm{~m}$ & 18-NM-64 & $\begin{array}{l}\text { http://www.puk.ac.za/fakulteite/natuur/n } \\
\text { m_data/data/static-content/tsumeb.dat }\end{array}$ \\
\hline
\end{tabular}

Despite this, the semiannual CR intensity variation with almost equal amplitude is observed simultaneously at all the stations, regardless of coordinates and altitude of the stations above sea level (Figure 8). It can be concluded that the semiannual CR intensity variation is mainly due to the position and opening of the IMF neutral layer at the intersection of which ground level enhancements of the galactic cosmic ray intensity are observed twice a year.

The seasonal variability of the number of earthquakes has been found in [Kropotkin, Lust 1974] only for weak and moderate earthquakes. For earthquakes with $M \geq 5.5$, everything is not cut and dried. Figure 9 shows the seasonal distribution of the number of strong earthquakes and the semiannual variation in the galactic cosmic ray intensity, averaged separately for stations of the Northern and Southern hemispheres (Table 3). The seasonal distribution of seismic activity has been assessed using data [https://earthquake.usgs.gov/earthquakes] on strong earthquakes with $M \geq 6$ over 50 years (Table 1).

We can see (Figure 9) that the seasonal distribution of the number of strong earthquakes seems to follow the semiannual CR intensity variation. Thus, the seasonal variability is characteristic not only of weak and moderate earthquakes, but of severe ones as well. In terms of seismology, it is very difficult to explain the presence of seasonal variability of earthquakes.

\section{IMPACT OF COSMIC RAYS ON ATMOSPHERIC PROCESSES}

Cosmic rays are the main source of the atmosphere ionization up to heights of $\sim 100 \mathrm{~km}$ [Usoskin, Kovaltsov, 2006; Usoskin et al., 2010], which leads to substantial physical changes in atmospheric air [Dorman, 2004; Harrison, Tammet, 2008]. Resulting ions are involved in many atmospheric processes: in the formation of the cloud cover [Pudovkin, Veretenenko,
1995; Svensmark, 1998; Marsh, Svensmark, 2000; Pallé et al., 2004; Usoskin et al., 2004; Usoskin, Kovaltsov, 2006; Voiculescu et al., 2006], in the formation of precipitation [Kniveton, 2004] and aerosols [Lee et al., 2003; Mironova et al., 2008; Lushnikov et al., 2014], and affect the atmosphere transparency [Kudryavtsev, Jungner, 2008, 2011; Roldugin, Tinsley, 2004], the global electric circuit [Harrison, 2004; Tinsley, 2000; Ermakov, Stozhkov, 2004; Tinsley, Zhou, 2006], and cyclogenesis in the middle and high latitudes [Tinsley et al., 1989; Tinsley, 2012; Veretenenko, Thejll, 2004].

Considerable variations have been found in the general cloud cover, which are associated with CR intensity variations during FD of galactic CR and solar CR flares [Veretenenko, Pudovkin, 1994; Pudovkin, Veretenenko, 1995]. It has been established [Svensmark, 2000] that the cloud cover $S$ and CR intensity $I$ variations are related by $\delta S / S=k \delta I / I$, where $k \approx 0.2$ up to $10 \%$. The correlation analysis has shown the presence of a high positive correlation (the correlation coefficient of 0.80) [Chukin, 2007] between the CR intensity and the amount of lowlevel clouds (680 hPa and more [Hahn et al., 2001]). For medium-level (440-680 hPa) and high-level (440 $\mathrm{hPa}$ or less) clouds there is a faint insignificant negative correlation with the CR intensity $(-0.54$ and -0.48 respectively). The 11 -year CR intensity variations by \pm 10 $\%$ are shown to cause changes in the cloud cover by over $\pm 1 \%$, and the 11 -year variation in the global cloud cover causes changes in solar energy flux near Earth's surface with an amplitude of $10 \mathrm{~W} / \mathrm{m}^{2}$ [Chukin, 2007].

To explain the CR effect on weather events, mechanisms have been proposed [Krymsky, 2006; Kudryavtsev, Jungner, 2011] where the atmosphere ionization by CR whose intensity is modulated by solar activity is considered to be the main process. Laboratory experiments at EONR [Duplissy et al., 2010] and in Copenhagen [Enghoff et al., 2011] confirm the existence of the proposed mechanisms. 


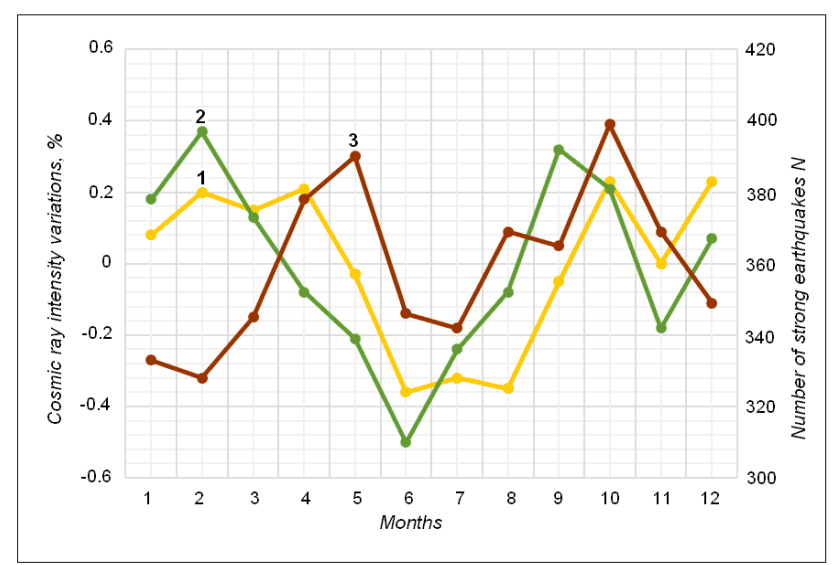

Figure 9. Semiannual CR intensity variation at stations of the Northern (curve 1) and Southern (curve 2) hemispheres and seasonal distribution of the number of strong earthquakes (curve 3)

These mechanisms of CR effect on weather events account for how the atmosphere ionization by $\mathrm{CR}$ leads to temperature and pressure variations and hence to a change in the atmospheric circulation, through which the thermal energy is spread over the atmosphere. The atmospheric circulation changes lead to significant changes in atmospheric processes.

\section{ATMOSPHERIC PROCESSES AND SEISMICITY}

Evidence for the possible effect of atmospheric processes on seismicity was reported as far back as the beginning of the last century [Golitsyn, 1912; Gutenberg 1935]. The analysis of synoptic situations has revealed [Sytinsky, 1987; Sytinsky, Oborin, 1997; Bokov, 2004; Bokov, Vorob'ev, 2007] that before a severe earthquake around the epicenter at a distance of about thousand kilometers there are significant changes in atmospheric processes.

In the troposphere, vortices constantly arise, evolve, and disappear. Some are small and imperceptible, others, such as cyclones and anticyclones, are large-scale and markedly affect Earth's climate. A cyclone is a vortex with decreasing pressure toward the center; an anticyclone has a reverse pressure distribution. In the Northern Hemisphere in a cyclone winds blow counterclockwise, deviating in the lower layer to the center; in the Southern Hemisphere, clockwise (in an anticyclone, winds blow just the opposite). In moderate and polar latitudes, extratropical cyclones occur which, having at the initial stage a diameter of about one thousand kilometers, reach a diameter of several thousands of kilometers. The diameter of cyclones that appear in tropical latitudes is hundreds of kilometers. Nonetheless, large pressure gradients and wind speeds may promote conversion of tropical cyclones as they evolve into extratropical ones. The presence of the Coriolis force due to the Earth rotation causes cyclones to occur continually. The energy of a medium cyclone is comparable to the total annual energy of all earthquakes [Yaroshevich, 2019]. At the stage of formation, a cyclone is a low pressure center [Khrgian, 1986]. Pressure and wind gradients at the initial stage of a cyclone are weak; the atmospheric front is slightly disturbed.

A number of recent works [Bokov et al., 2011; Bokov, Vorob'ev, 2012, 2013, 2014, 2016] have studied the impact of atmospheric circulation on seismicity. It has been found out that it is precisely the atmospheric circulation that causes enhancement of some geophysical precursors: geoacoustic noise, radon emission, changes in the water level, deformation and tilts of the earth's crust [Bokov, Vorob'ev, 2012, 2014]. When considering the impact of atmospheric processes on the seasonal variability of the number of strong earthquakes for the Caucasus, Kuril Islands, Japan, Turkey, and Greece in [Bokov, Vorob'ev, 2007; Bokov, 2010], it has been shown that the number of strong earthquakes increases with increasing frequency of occurrence of traveling cyclones and anticyclones.

Every year in the atmosphere there are about $150 \mathrm{cy}-$ clones and 60 anticyclones. In an anticyclone, additional pressure on a horizontal surface (excessive load) is as high as $5 \cdot 10^{8} \mathrm{~kg} / \mathrm{km}^{2}$ [Bokov, Lebedev, 2017]. The opposite situation occurs in a cyclone. This gives rise to fluctuations in the earth's crust (Love surface seismic waves [http://www.mining-enc.ru/s/ sejsmicheskie-volny]). If the anticyclone - cyclone boundary is located above the fault and passes along it, the difference between effects on different sides of the fault can trigger an earthquake [Bokov, 2004; Bokov, Vorob'ev, 2014; Bokov, Lebedev, 2017]. As a result of studies of the relationship between atmospheric processes and seismic activity, a seismosynoptic method for short-term prediction of earthquakes with a 2-3 day lead time has been proposed. It has a forecast success rate of about $75 \%$ for all earthquakes: weak, moderate, and strong [Bokov, Vorob'ev, 2014; Bokov, Lebedev, 2017]. This confirms that continuously traveling air vortices [Bokov, 2004] together with endogenous processes [Gokhberg et al., 1983] cause changes in the stress-strain state of the earth's crust and generate fluctuations in it.

\section{CONCLUSION}

The number of severe earthquakes on the planet increases during the decline phase of solar activity when 
charged particle fluxes from high-latitude coronal holes enhance, as well as at solar minimum when the galactic cosmic ray intensity is maximum.

The number of earthquakes has been demonstrated to increase after Forbush decreases with a delay from $\sim 1$ to $\sim 6$ days depending on the Forbush decrease amplitude, and after a GLE event the number of earthquakes increases on the $\sim 8$ th day.

There is a semiannual variation in the number of strong earthquakes, which seems to follow the semiannual variation in cosmic rays with a delay of $\sim 1-2$ months.

It is assumed that solar activity and Earth's seismicity is indirectly related through modulation of galactic cosmic rays and atmospheric processes, which trigger earthquakes in regions where the situation has been prepared by tectonic activity.

The work is based on experimental data from the Unique Research Facility URF-85 "Russian National Network of Cosmic Ray Stations".

This work was performed with budgetary funding of Basic Research program No. 0331-2019-0013 "Manifestation of processes of the deep geodynamics in geospheres as derived from monitoring of the geomagnetic field, ionosphere, and cosmic rays".

\section{REFERENCES}

Belov A.V., Gushchina R.T., Balabin YU.V. Annual variation and heliolatitude dependence of cosmic ray density. Izvestiya RAN. Seriya fizicheskaya [Bulletin of the Russian Academy of Sciences. Physics]. 2015, no. 5, pp. 672-675. (In Russian). DOI: 10.7868/S0367676515050178.

Bokov V.N. Variability of atmospheric circulation - the initiator of strong earthquakes. Ural'skii geofizicheskii vestnik [Ural Geophysical Bulletin]. 2004, no. 6, pp. 5-11. (In Russian).

Bokov V.N. On the relationship of atmospheric circulation and seismicity in the range of seasonal variability. Uchenye zapiski RGGMU [Scientific Notes of the RSMU]. 2010, no. 14, pp. 89-100. (In Russian).

Bokov V.N., Lebedev S.V. Exogenous processes and seismicity. Triggernye effekty $v$ geosistemakh [Trigger Effects in Geosystems]. Moscow, GEOS Publ., 2017, pp. 379-386. (In Russian).

Bokov V.N., Vorob'ev V.N. On the relationship of strong earthquakes with atmospheric circulation in the seasonal and interannual ranges of variability. Sbornik trudov konferentsi "Yubeleinye chteniya pamyati A.L. Chizhevskogo, posvyashchennye 110-letiyu uchenogo" [Proceedings of the Conference "Anniversary Readings in Memory of A.L. Chizhevsky Dedicated to the $110^{\text {th }}$ Anniversary of the Scientist" $]$. St. Petersburg, Politekhnicheskii universitet Publ., 2007, pp. 51-56. (In Russian).

Bokov V.N., Vorob'ev V.N. The effect of atmospheric circulation on the inclination of the Earth. Uchenye zapiski $R G G M U$ [Scientific Notes of the RSMU]. 2012, no. 26 , pp. 173-184. (In Russian).

Bokov V.N., Vorob'ev V.N. Variability of geoacoustic emissions and changes in atmospheric circulation. Uchenye zapiski RGGMU [Scientific Notes of the RSMU]. 2013, no. 31, pp. 173-184. (In Russian).

Bokov V.N., Vorob'ev V.N. Monitoring of geophysical precursors and earthquake prediction. Uchenye zapiski $R G G$ $M U$ [Scientific Notes of the RSMU]. 2014, no. 36, pp. 128138. (In Russian).

Bokov V.N., Vorob'ev V.N. Variations in the surface temperature of the Earth's crust under the influence of atmospheric pressure variability. Uchenye zapiski RGGMU [Scientific Notes of the RSMU]. 2016, no. 43, pp. 106-115. (In Russian).

Bokov V.N., Gutshabash E.Sh., Potikha L.Z. Atmospheric processes as a trigger effect of earthquakes. Uchenye zapiski $R G G M U$ [Scientific Notes of the RSMU]. 2011, no. 18, pp. 173-184. (In Russian).

Chukin V.V. Correlation data on the relationship between the flux of cosmic rays and the global number of clouds. Fundamental'nye issledovaniya [Basic Research]. 2007, no. 7, pp. 78-79. (In Russian).

Dorman L. Cosmic Rays in the Earth's Atmosphere and Underground. Dordrecht, Springer Netherlands, 2004, 862 p. DOI: 10.1007/978-1-4020-2113-8.

Dorman L.I., Luzov A.A., Mamrukova V.P. Annual variations of cosmic rays and changes in the intensity of cosmic radiation in the function of the heliolatitude of the Earth. Doklady Akademii nauk SSSR [Doklady of the Academy of Sciences of the USSR]. 1967, no. 4, pp. 833-836. (In Russian).

Duplissy J., Enghoff M.B., Aplin K.L., Arnold F., Aufmhoff H., Avngaard M., Baltensperger U., et al. Results from the CERN pilot CLOUD experiment. Atmos Chem. Phys. 2010, vol. 10 no. 4, pp. 1635-1647. DOI: 10.5194/acp-101635-2010.

Enghoff M.B., Pedersen J.O.P., Uggerhøj U.I., Paling S.M., Svensmark H. Aerosol nucleation induced by a high energy particle beam. Geophys. Res. Lett. 2011, vol. 38, no. 9, L09805. DOI: 10.1029.2011GL047036.

Ermakov V.I., Stozhkov Y.I. Thunderstorm cloud physics. Preprint no. 2. Moscow, Lebedev Physical Institute Publ., 2004, 36 p. (In Russian).

Gokhberg M.B., Gufel'd I.L., Dobrovol'sky I.N., Nersenov I.L. Preparation processes, signs and harbingers of crustal earthquakes. Izvestiya AN SSSR. Fizika Zemli [Izvestiya of the Academy of Sciences of the USSR. Physics of the Solid Earth]. 1983, no. 2, pp. 59-67. (In Russian).

Golitsyn B.B. Lektsii po seismometrii [Lectures on seismometry]. St. Petersburg, Imperatorskaya AN Publ., 1912, 486 p. (In Russian).

Gutenberg B. Osnovy seysmologii [Seismology Basics], Moscow, Leningrad, ONTI Publ., 1935, 146 p. (In Russian).

Gutenberg B., Richter C.F. Seismicity of the Earth and associated Phenomena. Princeton, Princetion Univ. Press, 1954, $310 \mathrm{p}$.

Hahn C.J., Rossow W.B., Warren S.G. ISCCP cloud properties associated with standard cloud types identified in individual surface observations. J. Climate. 2001, vol. 14, pp. 11$28 . \quad$ DOI: 10.1175/15200442(2001)014<0011:ICPAWS>2.0.CO;2.

Harrison R.G. The global atmospheric electrical circuit and climate. Sur. Geophys. 2004, vol. 25, pp. 441-484. DOI: $10.1007 / \mathrm{s} 10712-004-5439-8$.

Harrison R.G., Tammet H. Ions in the terrestrial atmosphere and other solar system atmospheres. Space Sci. Rev. 2008, vol. 137, pp. 107-118. DOI: 10.1007/s11214-008-9356-x.

Hatton C.J., Carmichael H. Experimental invectigation of the NM-64 Neutron monitor. Canad. J. Phys. 1964, vol. 42, pp. 2443-2472.

Kniveton D.R. Precipitation, cloud cover and Forbush decreases in galactic cosmic rays. J. Atmos. Solar Terr. Phys. 2004, vol. 66, iss. 13-14, pp. 1135-1142. DOI: 10.1016/ j.jastp.2004.05.010.

Khrgian A.Kh. Fizika atmosfery [Atmospheric physics]. Moscow, MGU Publ., 1986, 328 p. (In Russian).

Kropotkin P.N., Lyustikh A.E. Seasonal periodicity of earthquakes and Newton-Mach principle. Doklady Akademii nauk SSSR [Doklady of the Academy of Sciences of the USSR]. 1974, no. 5, pp. 1061-1064. (In Russian). 
Krymsky G.F. Cosmic rays and the Earth's atmosphere: facts and hypotheses. Solnechno-zemnaya fizika [SolarTerrestrial Physics]. 2006, iss. 9, pp. 44-46. (In Russian).

Krymsky G.F., Krivoshapkin P.A., Mamrukova V.P., Skripin G.V. Effects of the interaction of the heliomagnetosphere with the galactic field in cosmic rays. Geomagnetizm $i$ aeronomiya [Geomagnetism and Aeronomy]. 1981, no. 5, pp. 923-928. (In Russian).

Krymsky G.F., Krivoshapkin P.A., Mamrukova V.P., Gerasimova S.K. Heliospheric modulation of high-energy cosmic rays: II. Deformation of the neutral surface. J. Exp. Theor. Phys. 2007, vol. 104, no. 2, pp. 196-200. DOI: 10.1134/ S1063776107020045.

Krymsky G.F., Krivoshapkin P.A., Mamrukova V.P., Gerasimova S.K. North-south asymmetry of the heliosphere from cosmic-ray observations. Astronomy Lett. 2009, vol. 35 , pp. 333-337. DOI: 10.1134/S1063773709050077.

Krymsky G.F., Krivoshapkin P.A., Gerasimova S.K., Gololobov P.Yu. Cosmic-ray anisotropy and density near the neutral sheet of the interplanetary magnetic field. Astronomy Letters. 2012, vol. 38, no. 9, pp. 605-608. DOI: 10.1134/ S1063773712080038.

Kudryavtsev I.V., Jungner H. To the link between anomalies of the Earth's cloud cover at various heights and variations of the cosmic ray intensity. Solnechno-zemnaya fizika [SolarTerrestrial Physics]. 2008, iss. 12, pp. 301-304. (In Russian).

Kudryavtsev I.V., Jungner H. Variations in atmospheric transparency under the action of galactic cosmic rays as a possible cause of their effect on the formation of cloudiness. Geomagnetizm i aeronomiya [Geomagnetism and Aeronomy]. 2011, vol. 51, 656. DOI: 10.1134/S0016793211050100.

Lee S.H., Reeves J.M., Wilson J.C., Hunton D.E., Viggiano A.A., Miller T.M., Ballenthin J.O., Lait L.R. Particle formation by ion nucleation in the upper troposphere and lower stratosphere. Science. 2003, vol. 301, pp. 1886-1889. DOI: 10.1126/science.1087236.

Lushnikov A.A., Lyubovtseva Yu.S., Gvishiani A.D., Zagaynov V.A. Nanoaerosol formation in the troposphere under the action of cosmic radiation. Izvestiya. Atmospheric and Oceanic Physics. 2014, vol. 50, no. 2, pp. 152-159. DOI: 10.1134/S0001433814020078.

Marsh N.D., Svensmark H. Low clouds properties influenced by cosmic rays. Phys. Rev. Lett. 2000, vol. 85, pp. 5004-5007. DOI: 10.1103/PhysRevLett.85.5004.

Mironova I.A., Desorgher L., Usoskin I.G., Flückiger E.O., Bütikofer R. Variations of aerosol optical properties during the extreme solar event in January 2005. Geophys. Res. Lett. 2008, vol. 35, L8610. DOI: 10.1029/2008GL035120.

Pallé E., Butler C.J., O’Brien K. The possible connection between ionization in the atmosphere by cosmic rays and low level clouds. J. Atm. Solar-Terr. Phys. 2004, vol. 66, pp. 1779-1790. DOI: 10.1016/j.jastp.2004.07.041.

Pudovkin M.I., Veretenenko S.V. Cloudiness decreases associated with Forbush-decreases of galactic cosmic rays. $J$. Atmos. Terr. Phys. 1995, vol. 57, no. 11, pp. 1349-1355. DOI: 10.1016/0021-9169(94)00109-2.

Roldugin V.C., Tinsley B.A. Atmospheric transparency changes associated with solar wind-induced atmospheric electricity variations. J. Atmos. Solar-Terr. Phys. 2004, vol. 66, iss. 13-14, pp. 1143-1149. DOI: 10.1016/j.jastp.2004.05.006.

Russo P. Zemletryaseniya [Earthquakes]. Moscow, Progress Publ., 1966, 247 p. (In Russian). (French edition: Rousseau P. Les Tremblements de Terre [Earthquakes]. Hachette, 1961. 269 p.).

Sobolev G.A., Shestopalov I.P., Kharin E.P. Geoeffective solar flares and Earth's seismic activity. Fizika Zemli [Izvestiya. Physics of the Solid Earth]. 1998, no. 7, pp. 85-90. (In Russian).

Sytinsky A.D. Svyaz'seismichnosti Zemli s solnechnoi ak- tivnost'yu i atmosfernymi protsessami [The relationship of Earth's seismicity with solar activity and atmospheric processes]. Leningrad, Gidrometeoizdat Publ., 1987, 100 p. (In Russian).

Sytinsky A.D. On the relationship of earthquakes with solar activity. Izvestiya Akademii nauk SSSR. Fizika Zemli [Izvestiya of the Academy of Sciences of the USSR. Physics of the Solid Earth]. 1989, no. 2, pp. 13-29. (In Russian).

Sytinsky A.D., Oborin D.A. Influence of disturbances of the interplanetary medium on the seismicity and atmosphere of the Earth. Geomagnetizm i aeronomiya [Geomagnetism and Aeronomy]. 1997, vol. 37, pp. 138-141. (In Russian).

Svensmark H. Influence of cosmic rays on Earth's climate. Phys. Rev. Lett. 1998, vol. 81, no. 22, pp. 5027-5030. DOI: 10.1103/PhysRevLett.81.5027.

Svensmark H. Cosmic rays and Earth's climate. Space Sci. Rev. 2000, vol. 93, pp. 175-185. DOI: 10.1023/A:1026 592411634

Tinsley B.A. Influence of solar wind on the global electric circuit, and inferred effects on cloud microphysics, temperature, and dynamics in the troposphere. Space Sci. Rev. 2000, vol. 94, no. 1-2, pp. 231-258. DOI: 10.1023/A:1026775408875.

Tinsley B.A. A working hypothesis for connections between electrically-induced changes in cloud microphysics and storm vorticity, with possible effects on circulation. $A d v$. Space Res. 2012, vol. 50, iss. 6, pp. 791-805. DOI: 10.1016/ j.asr.2012.04.008

Tinsley B.A., Zhou L. Initial results of a global circuit model with stratospheric and tropospheric aerosols. J. Geophys. Res. 2006, vol. 111, D16205. DOI: 10.1029/2005JD006988.

Tinsley B.A., Brown G.M., Scherrer P.H. Solar variability influences on weather and climate: Possible connections through cosmic ray fluxes and storm intensification. J. Geophys. Res. 1989, vol. 94, no. D12, pp. 14783-14792. DOI: $10.1029 / J D 094 i D 12 p 14783$.

Usoskin I.G., Kovaltsov G.A. Cosmic ray induced ionization in the atmosphere: Full modeling and practical applications. J. Geophys. Res. 2006, vol. 111, D21206. DOI: 10.1029/ 2006JD007150.

Usoskin I.G., Gladysheva O.G., Kovaltsov G.A. Cosmic ray induced ionization in the atmosphere: Spatial and temporal changes. J. Atmos. Solar-Terr. Phys. 2004, vol. 66, no. 18, pp. 1791-1796. DOI: 10.1016/j.jastp.2004.07.037.

Usoskin I.G., Kovaltsov G.A., Mironova I.A. Cosmic ray induced ionization model CRAC: CRII: an extension to the upper atmosphere. J. Geophys. Res. 2010, vol. 115, D10302. DOI: 10.1029/2009JD013142.

Veretenenko S.V., Pudovkin M.I. Effects of Forbush cosmicray drops in variations of total cloud cover. Geomagnetizm i aeronomiya [Geomagnetism and Aeronomy]. 1994, no. 4, pp. 38-44. (In Russian).

Veretenenko S., Thejll P. Effects of energetic solar proton events on the cyclone development in the North Atlantic. $J$. Atmos. Solar Terr. Phys. 2004, vol. 66, no. 5, pp. 393-405. DOI: 10.1016/j.jastp.2003.11.005.

Voiculescu M., Usoskin I.G., Mursula K. Different response of clouds to solar input. Geophys. Res. Lett. 2006, vol. 33, L21802. DOI: 10.1029/2006GL027820.

Yanchukovsky V.L. Multichannel cosmic rays observation complex. Solnechno-zemnaya fizika [Solar-Terrestrial Physics]. 2010, iss. 16, pp. 107-109. (In Russian).

Yanchukovsky V.L., Yanchukovsky A.L., Krasavin V.V., et al. Multiple Neutron Monitor. Issledovaniya po geomagnetizmu, aeronomii i fizike Solntsa [Research on Geomagnetism, Aeronomy and Solar Physics]. 1971, iss. 20, pp. 396-404. (In Russian).

Yaroshevich M.I. On some similar regularities of cyclonic and seismic activity. Izvestiya. Atmospheric and Oceanic Physics. 2019, vol. 55, no. 3, pp. 281-284. DOI: 10.1134/ 
S0001433819020154.

URL: http://cosm-rays.ipgg.sbras.ru (accessed March 10, 2020).

URL: http://www.wdcb.ru/stp/solar/sunspots.ru.html (accessed March 10, 2020).

URL: http://www.meteo-dv.ru/geospace/AverageMonthW (accessed March 10, 2020).

URL: http://sidc.oma.be (accessed March 10, 2020).

URL: http://193.232.24.200/nvbk/main.htm (accessed March 10, 2020).

URL: https://earthquake.usgs.gov/earthquakes (accessed March 10, 2020).

URL: https://earthquake.usgs.gov/earthquakes/browse/significant.php (accessed March 10, 2020).

URL: http://www.rus-stat.ru/index.php?vid=1\&year=2001
$\& \mathrm{id}=49 \&$ page $=2($ accessed March 10, 2020 $)$

URL: http://cgm.iszf.irk.ru/ (accessed March 10, 2020).

URL: http://www.puk.ac.za/fakulteite/natuur/nm_data/ data/nmd_e.html (accessed March 10, 2020).

URL: http://www.nmdb.eu (accessed March 10, 2020).

URL: http://cr0.izmiran.ru/mosc (accessed March 10, 2020).

URL: http://cosmicrays.oulu.fi (accessed March 10, 2020).

URL: http://www.mining-enc.ru/s/sejsmicheskie-volny (accessed March 10, 2020).

How to cite this article

Yanchukovsky V.L. Solar activity and Earth seismicity.SolarTerrestrial Physics. 2020. Vol. 6. Iss. 4. P. 67-77. DOI: 10.12737/stp71202109. 